\section{BOOK REVIEW}

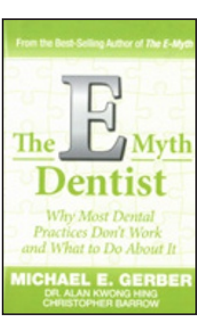

\section{THE E-MYTH DENTIST - WHY MOST PRACTICES DON'T WORK AND WHAT TO DO ABOUT IT}

\author{
M. E. Gerber, A. K. Hing, C. Barrow \\ Michael E. Gerber Companies \\ price €14.84; pp 220 \\ ISBN 9781618350251
}

The E-myth dentist - why most practices don't work and what to do about it by Michael E. Gerber, undertakes to fill the knowledge gap created by universities where dentists are left with no formal training in business. It aims to give the reader a complete toolkit for either starting a successful practice or maximising an existing practice's financial performance. Thus, the target audience are principal dentists or anyone looking to become a principal dentist.

The beginning of the book makes it clear that although the average dentist may well possess the resources to provide a great dental service, they rarely possess the ability to run a successful small business from the outset.

The main theme of the book was introduced early on: developing the ability to shift ones thinking from tactical thinking (working 'in' your business) to strategic thinking (working 'on' your business). The eventual goal of strategic thinking was to create a 'turn-key' system, where the principal does not need to be present for continual growth and financial success.

At last, here was the book that was about to deliver the dream!

The middle chapters of the book were all very informative but I found the chapter dealing with money the most useful. Plain language and simple scenarios were used to explain income, profit, flow and equity. The book retains engagement by including chapters written by co-authors Alan Kwong Hing and Chris Barrow. Their experiences and ideas are very insightful.

The book took a fascinating turn towards the end. The psychology behind the development of leadership and the different types of leadership was examined before being developed into the psychology behind taking action, confronting fear and implementing changes to produce consistent success. Creating a story about your practice was something I had never really considered. The idea that this can then become the heart of the practice and then a unique selling point to patients I thought was very interesting.

In conclusion, this book provides all the necessary tools for success in practice. It helps make you take the sanctity of time seriously, blocking time for entrepreneurial work yet still enjoy a life-work balance. It gives refreshing, ethical and relevant advice and is loaded with innovative ways to create a thriving dental business.

G. ISHERWOOD

\title{
ONE GOOD DEED CAN CHANGE A LIFE
}

The Dental Wellness Trust, a charity founded by dentist Linda Greenwall, is offering patients the chance to buy a Good Deed Toothbrush, designed by dentists, to help the 75\% of children worldwide who do not have access to a toothbrush. For every brush sold an identical one will be given to a child somewhere in the world who does not have one.

This simple, philanthropic, new initiative will allow every dental practice in the UK to effortlessly help give away 30,000 toothbrushes this year with an aim of building this figure to 3 million in the years to come.

According to Dr Greenwall the aim is to create a simple transaction. Dr Greenwall said: 'We are advising the public that to get toothbrushes to a child in need, all they have to do is buy one for themselves from their dental practice. The money raised buys a brush for a child in the UK or the developing world who doesn't have access to even the most basic means of dental health.'

This is only a small part of the work carried out by the Dental Wellness Trust which includes providing supervised tooth brushing
$75 \%$ of the world's children have no access to a toothbrush to clean their teeth.

A 49p toothbrush can make all the difference

programmes for 1 million children in South Africa, and an evening programme called LiveSmart which aims to help 5,000 children clean up each night by providing them with brushes, toothpaste and soap (for which the organisation is lobbying for donations from oral health companies and hotels) and teaching them effective oral hygiene methods. Dentists from all over the world have donated their time to be involved, and the supervised brushing sessions have been shown to significantly improve both the oral and overall health of the participants. In the Philippines alone the programme was shown to have improved tooth care by $40 \%$ in one year.

The charity also works with elderly, disabled and marginalised people in the UK, Eastern Europe, Ghana, Ruwanda, South Africa and Israel to help improve their access to good oral health.

\section{NEW COVER SERIES CELEBRATES 80 YEARS OF THE BDA MUSEUM}

To celebrate the 80th anniversary of the BDA Museum, the $B D J$ has commissioned a photographic cover series highlighting landmarks in dental history. The 'History of Dentistry in 12 objects' aims to demonstrate progress in dentistry by placing an old object in a modern environment, causing the reader to look twice at the picture. Each landmark was selected by the BDA museum volunteer team after much debate!

Establishing a museum at the BDA was seen as important and beneficial from the 1920s but it wasn't until the BDA transferred to Hill Street in 1935 that suitable display space was acquired. The Representative Board approved that a museum should be formed in memory of James Smith Turner, the first Honorary Secretary of the Association. In June 1935 George Northcroft was appointed as the first honorary curator. The
Association already possessed a number of items collected by Lilian Lindsay including a set of jaws in a tree trunk from Fiji and during the next few years generous donations from members and dental manufacturers expanded the collection greatly. Notable additions included the dental surgery furniture used by Sir John Tomes and a glass kidney display case donated by S. S. White

The museum continues to collect items which represent current developments in dentistry and now has a collection of over 25,000 objects spanning 500 years of history. The first cover in the series shows London in 1848. The drill works similarly to an egg whisk principle and includes an interchangeable, right angled head. Requiring two hands to operate it, cavity preparation remained slow and difficult. The treadle drill, invented by James B. Morrison in 1871 proved to be the next major step forward. 